\title{
DOCUMENTO
}

\section{Para una reforma del sistema financiero y monetario internacional en la perspectiva de una autoridad pú- blica de ámbito mundial}

\author{
Nota del Consejo Pontificio Justicia y Paz'
}

\section{Presentación}

La actual situación del mundo exige una acción de conjunto que tenga como punto de partida una clara visión de todos los aspectos económicos, sociales, culturales y espirituales. La Iglesia, experta en humanidad, lejos de pretender mezclarse en la política de los Estados, sólo desea una cosa: bajo la guía del Espíritu Defensor, continuar la obra misma de Cristo, quien vino al mundo para dar testimonio de la verdad, para salvar y no para juzgar, para servir y no para ser servido².

Con estas palabras, en su profética y siempre actual encíclica Populorum progressio de 1967, Pablo VI delineaba de forma clara las trayectorias de la íntima relación de la Iglesia con el mundo: trayectorias que se entrecruzan en el profundo valor de la dignidad del ser humano y en la búsqueda del bien común, y que además hacen a los pueblos responsables y libres de actuar según sus más altas aspiraciones.

La crisis económica y financiera que atraviesa el mundo actual convoca a todos, personas y pueblos, a un profundo discernimiento sobre los principios y los valores culturales y morales fundamentales para la convivencia social, aunque no sólo, pues la crisis compromete a los agentes privados y a las autoridades públicas

\footnotetext{
${ }^{1}$ Traducción del original italiano (www.vatican.va), revisada por la redacción de RFS a partir del texto en castellano de Radio Vaticana.

2 PABlO VI (1967) Populorum progressio, n. 13 [La cita final, de la Constitución pastoral Gaudium et Spes, n. 3, \&2 (ndt)]
} 
nacionales, regionales e internacionales a una seria reflexión sobre las causas y las soluciones de naturaleza política, económica y técnica.

En esta perspectiva, la crisis, enseña Benedicto XVI,

nos obliga a revisar nuestro camino, a darnos nuevas reglas y a encontrar nuevas formas de compromiso, a apoyarnos en las experiencias positivas y a rechazar las negativas. De este modo, la crisis se convierte en ocasión de discernir y proyectar de un modo nuevo. Conviene afrontar las dificultades del presente en esta clave, de manera confiada, más que resignada ${ }^{3}$.

Los mismos líderes del G20, en la declaración adoptada en Pittsburgh el año 2009 , han afirmado que

La crisis económica demuestra la importancia de entrar en una nueva etapa de actividad económica mundial sostenible basada en la responsabilidad'.

Recogiendo el llamamiento del Papa y haciendo, al mismo tiempo, propias las preocupaciones de los pueblos -sobre todo aquellos que sufren más los efectos de la situación actual- el pontificio consejo "Justicia y Paz", respetando las competencias de las autoridades civiles y políticas, desea proponer y compartir la propia reflexión Para una reforma del sistema financiero y monetario internacional en la perspectiva de una autoridad pública de ámbito mundial.

Esta reflexión desea ser una contribución a los responsables de la tierra y a todos los hombres de buena voluntad, un gesto de responsabilidad, no sólo respecto de las generaciones actuales, sino sobre todo de las futuras, a fin de que no se pierda jamás la esperanza en un futuro mejor y la confianza en la dignidad y en la capacidad de bien de la persona humana.

Peter K. A. TURKSON, cardenal presidente de Justicia y Paz Mario Toso, secretario de Justicia y Paz

\footnotetext{
${ }^{3}$ BeNEDICTO XVI (2009) Caritas in veritate, n. 21 [En el original en cursiva (ndt)].

${ }^{4}$ Leader's Statement, Cumbre de Pittsburgh, 24/25-IX-2009, anexo 1.
} 


\section{[1] Preliminar}

Toda persona y toda comunidad de personas son parte y responsables de la promoción del bien común. Fieles a su vocación de naturaleza ética y religiosa, las comunidades de creyentes deben en primer lugar preguntarse sobre la adecuación de los medios de que dispone la familia humana para la realización del bien común mundial. La lglesia, por su parte, está llamada a animar, indistintamente en todos, aquella voluntad de participar

conjunto ingente de esfuerzos realizados por el hombres a lo largo de los siglos para lograr mejores condiciones de vida [que, considerado en sí mismo,] responde a la voluntad de Dios ${ }^{5}$.

\section{Desarrollo económico y desigualdades}

[2] La grave crisis económica y financiera que hoy atraviesa el mundo, encuentra su origen en múltiples causas. Sobre la pluralidad y el peso de estas causas persisten opiniones diversas: algunos subrayan, sobre todo los errores inherentes a las políticas económicas y financieras; otros sobre las debilidades estructurales de las instituciones políticas, económicas y financieras; otros, en fin, las atribuyen a fallos de naturaleza ética en todos los niveles, en el marco de una economía mundial cada día más dominada por el utilitarismo y el materialismo. En las distintas etapas de desarrollo de la crisis encontramos siempre una combinación de errores técnicos y de responsabilidades morales.

En el caso del intercambio de bienes materiales y de servicios, son la naturaleza, la capacidad productiva y el trabajo en sus múltiples formas, quienes ponen un límite a las cantidades, determinando un conjunto de costes y de precios que permite, bajo ciertas condiciones, una asignación eficiente de los recursos disponibles.

Pero en materia monetaria y financiera, las dinámicas son distintas. En los últimos decenios, han sido los bancos los que han extendido el crédito, que ha generado moneda, que a su vez ha exigido una posterior expansión del crédito. De este modo el sistema económico ha sido empujado hacia una espiral inflacionista que, inevitablemente, ha encontrado un límite en el riesgo sostenible para los institutos de crédito, sometidos a un ulterior peligro de quiebra, con consecuencias negativas para todo el sistema económico y financiero.

\footnotetext{
${ }^{5}$ Concilio Vaticano II (1965) Constitución pastoral Gaudium et Spes, n. 34.
} 
[3] Después de la segunda guerra mundial, las economías nacionales progresaron, aunque con enormes sacrificios de millones, incluso miles de millones de personas, quienes con su comportamiento como productores y empresarios, por un lado, y como ahorradores y consumidores, por el otro, habían dado su confianza a una progresiva regulación del desarrollo de la moneda y de las finanzas, de acuerdo con el crecimiento real de la economía.

A partir de los años noventa del pasado siglo, se comprueba que la moneda y los títulos de crédito a nivel global aumentaron mucho más rápidamente que la producción de beneficios, incluso a precios corrientes. De todo ello derivó la formación de bolsas excesivas de liquidez y de burbujas especulativas que luego se transformaron en crisis de solvencia y de confianza que se propagaron y extendieron en el transcurso de los años.

En los años setenta y principios de los ochenta se produjo una primera crisis relativa a los precios del petróleo. Posteriormente hubo una serie de crisis en varios países en vías de desarrollo, como la primera crisis de México en los años ochenta, o también las de Brasil, Rusia y Corea; a continuación, nuevamente México en los años noventa, así como Tailandia y Argentina.

[4] La burbuja especulativa en la construcción y la reciente crisis financiera tienen el mismo origen: la excesiva acumulación global de moneda y de instrumentos financieros.

Mientras las crisis en los países en vías de desarrollo, que han estado a punto de implicar al sistema monetario y financiero global, han sido controladas con intervenciones de los países más desarrollados, la crisis que estalló en 2008, se caracterizó por un decisivo elemento de ruptura respecto a las precedentes. La crisis se originó en Estados Unidos, una de las áreas más relevantes para la economía y las finanzas mundiales, implicando a la moneda que todavía es referente para la gran mayoría de los intercambios internacionales.

Una orientación liberal-reticente respecto a las intervenciones públicas en los mercados-ha propiciado la quiebra de una importante entidad financiera internacional, pensando que así se podrían delimitar la crisis y sus efectos. Desafortunadamente, de ahí vino la propagación de la desconfianza que impulsó repentinos cambios de actitud, pidiendo intervenciones públicas de diverso tipo de enorme alcance (por encima del $20 \%$ del producto nacional) para bloquear los efectos negativos que habrían afectado a todo el sistema financiero internacional. 
Las consecuencias sobre la así denominada "economía real», a través de graves dificultades para algunos sectores -en primer lugar la construcción-y a causa de la difusión de expectativas desfavorables, han generado una tendencia negativa para la producción y el comercio internacional, con graves repercusiones en el empleo y con efectos de cuyo alcance probablemente aún no somos conscientes. Los costes para millones, e incluso algún millar de millones de personas, son enormes en los países desarrollados, pero más en los que están en vías de desarrollo.

[5] En países y áreas donde se carece todavía de los bienes más elementales como la salud, la alimentación y la protección ante las inclemencias climáticas, más de mil millones de personas se ven obligadas a sobrevivir con un ingreso medio diario de alrededor de un euro.

El bienestar económico global, medido en primer lugar por la renta, además de por la difusión de capacidades ${ }^{6}$, ha crecido en el curso de la segunda mitad del siglo XX, con un alcance y una rapidez que jamás había sido experimentada en la historia del género humano.

Pero también han aumentado enormemente las desigualdades en el interior de los diferentes países y entre ellos. Mientras que algunos países y algunas áreas económicas, las más industrializadas y desarrolladas, han visto crecer notablemente la renta, otros países han quedado de hecho excluidos del progreso económico general, e incluso ha empeorado su situación.

[6] Los peligros de un desarrollo económico, concebido en términos liberales fueron denunciados lúcida y proféticamente ya en 1967 por Pablo VI -a causa de sus nefastas consecuencias sobre los equilibrios mundiales y sobre la paz-, después del Concilio Vaticano II, con la encíclica Populorum progressio. El Papa indicó que la defensa de la vida y la promoción del progreso cultural y moral de las personas eran condiciones imprescindibles para la promoción de un auténtico desarrollo. Sobre tales fundamentos, Pablo Vl afirmaba que el desarrollo integral y planetario "es el nuevo nombre de la paz».?

Cuarenta años después, el Fondo Monetario Internacional reconoció en su "Informe anual" de 2007 la estrecha conexión entre un proceso de globalización que no

${ }^{6}$ Capabilities, en inglés en el original (ndt).

7 PABLO VI (1967) Populorum progressio, nn. 76 ss. ["El desarrollo es el nuevo nombre de la paz" no se encuentra en el texto, sino como epígrafe del n. 76. La misma idea en id. n. 5: "una acción concreta a favor del desarrollo integral del hombre y del desarrollo solidario de la humanidad" (ndt)]. 
hubiera sido gobernado adecuadamente por un lado y las fuertes desigualdades mundiales por otro ${ }^{8}$. Los modernos medios de comunicación hoy hacen que las desigualdades económicas, sociales y culturales existentes globalmente sean visibles a todos los pueblos, ricos y pobres, creando tensiones y enormes movimientos migratorios.

El proceso de globalización, sin embargo -hay que reconocerlo-, con sus aspectos positivos está en la base del gran desarrollo de la economía mundial del siglo XX. Merece la pena recordar que, entre 1900 y 2000 casi se ha cuadruplicado la población mundial y que la riqueza producida en todo el mundo creció mucho más rápidamente, de manera que la renta media "per cápita" haya aumentado aún más. En el mismo tiempo, sin embargo, no ha aumentado la equitativa distribución de la riqueza, más bien en muchos casos ha empeorado.

[7] Pero, ¿qqué es lo que ha empujado al mundo por esta dirección tan extremadamente problemática, también para la paz?

Ante todo, un liberalismo económico sin reglas ni controles, que es una ideología o forma de "apriorismo económico» que pretende que las leyes del funcionamiento del mercado y las denominadas leyes del desarrollo capitalista tienen su origen en la teoría, desorbitando algunos de sus aspectos. Una ideología económica que establezca "a priori" las leyes de funcionamiento del mercado y del desarrollo económico sin confrontarse con la realidad, corre el peligro de convertirse en un instrumento subordinado a los intereses de los países que gozan, de hecho, de una posición económica y financiera más favorable.

En ámbitos nacionales y regionales, aunque de manera imperfecta, con frecuencia existen reglas $y$ controles, que sin embargo tienen dificultad para iniciarse $y$ consolidarse en ámbitos internacionales.

[8] En la raíz de las disparidades y distorsiones del desarrollo capitalista se encuentra, en gran medida, además de la ideología del liberalismo económico, la ideología utilitarista, es decir la pretensión teóricopráctica según la cual «lo que es útil para el individuo conduce al bien de la comunidad». Es necesario reconocer que una afirmación semejante contiene un fondo de verdad, pero no podemos ignorar que no siempre lo que es útil individualmente, aunque legítimo, favorece el bien común. En más de una ocasión es necesario un espíritu de solidaridad que trascienda la utilidad personal a favor del bien de la comunidad.

${ }^{8}$ Cf. International Monetary Fund, Annual Report 2007, pp. 8 ss. 
En los años veinte del siglo pasado, algunos economistas ya pusieron en guardia para que no se diera un crédito excesivo a aquellas teorías que, en ausencia de reglas y controles, actualmente se han transformado en la ideología y la praxis internacionalmente dominante.

Un efecto ruinoso de estas ideologías, sobre todo en los últimos decenios del pasado siglo y primeros años del nuevo, fue el estallido de la crisis en la que aún se encuentra sumergido el mundo.

[9] Benedicto XVI, en su encíclica social, ha señalado de manera precisa la raíz de una crisis que no es solamente de naturaleza económica y financiera, sino sobre todo tipo moral, además de ideológica. La economía, en efecto -observa el Papa- tiene necesidad de la ética para su correcto funcionamiento, no de una ética cualquiera, sino de una ética amiga de la persona?. El Papa ha denunciado además el papel del utilitarismo y el individualismo, así como las responsabilidades de quienes los han asumido y difundido como guía para el comportamiento adecuado de aquellos actores económicos y políticos que actúan e interactúan en el contexto social. Benedicto XVI también ha señalado y denunciado a la «ideología de la tecnocracia» como nueva forma ideológica.

\section{El papel de la técnica y el desafío ético}

[10] El gran desarrollo económico y social del siglo pasado, ciertamente con luces pero también con sus graves sombras, se debe, en gran parte, al sostenido desarrollo técnico y, en décadas más recientes, a los progresos informáticos y a sus aplicaciones a la economía, en primer lugar a las finanzas.

Una interpretación lúcida actual de la "nueva cuestión social" ha de evitar el error, derivado también de la ideología neoliberal, de considerar que los problemas que hay que afrontar son de tipo exclusivamente técnico y que, en cuanto tales, escaparían al necesario discernimiento y valoración éticos. La encíclica de Benedicto XVI pone en guardia contra la "ideología tecnocrática", pues conduce a una absolutización de la técnica que tiende a producir una incapacidad de percibir todo aquello que no se explica por la pura materia ${ }^{10}$ y a minimizar el peso de

\footnotetext{
${ }^{9}$ BeNedICTO XVI (2009) Caritas sin veritate, n. 45.

10 BeNedICTO XVI (2009) Caritas sin veritate, n. 77.
} 
las decisiones individuales de las personas concretas que actúan en el sistema económico-financiero, reduciéndolas a meras variables técnicas. El rechazo de «algo más», comprendido como algo distinto de la técnica, no sólo hace imposible que se encuentren soluciones adecuadas para los problemas, sino que empobrece cada vez más, material y moralmente, a las víctimas más afectadas por la crisis.

[11] En un contexto de fenómenos complejos, no se puede desatender o subestimar la relevancia de los factores éticos y culturales. La crisis, en efecto, ha mostrado comportamientos egoístas, de codicia colectiva y de acaparamiento de bienes a gran escala. No podemos resignarnos a ver al hombre vivir como «un lobo para los otros hombres», según la concepción sostenida por Hobbes. En conciencia, nadie puede aceptar el desarrollo de algunos países en perjuicio de otros. Si no se pone remedio a las diversas formas de injusticia, los efectos negativos que se producirán a nivel social, político y económico originarán un clima de hostilidad creciente y de violencia llegando a desgastar las bases de las instituciones democráticas, aún de aquellas consideradas más sólidas.

[12] El reconocimiento de la primacía del "ser" respecto al "tener", de la ética respecto a la economía, debería llevar a que los pueblos de la tierra asumieran una "ética de la solidaridad" como principio inspirador de su acción, abandonando toda egoísmo mezquino y abrazando la lógica del bien común mundial que trasciende los meros intereses contingentes y particulares. En fin de cuentas, deberían mantener vivo el sentido de pertenencia a la familia humana, a partir de la común dignidad de todas las personas: por encima de la lógica de los intercambios a base de los parámetros y de sus formas justas, existe algo que es debido al hombre porque es hombre, en virtud de su eminente dignidad"1 .

En 1991, después del fracaso del colectivismo marxista, Juan Pablo II puso en guardia contra el peligro de una idolatría del mercado, que ignora la existencia de bienes que, por su naturaleza, no son ni pueden ser simples mercancías ${ }^{12}$. Hoy este aviso debe ser aceptado urgentemente y elegir aquél camino que esté más en sintonía con la dignidad y con la vocación trascendente de la persona y de la familia humana.

\footnotetext{
11 JuAn Pablo II (1991) Centesimus annus, n. 70.

12 JuAn Pablo II (1991) Centesimus annus, n. 40.
} 


\section{El gobierno de la globalización}

[13] En el camino hacia la construcción de una familia humana más fraterna y justa, antes aún de un nuevo humanismo abierto a la trascendencia, la enseñanza de Juan XXIII es muy actual. En su profética encíclica Pacem in Terris (1963) advertía que el mundo se dirigía hacia una cada vez mayor unificación. Levantaba constancia del hecho de que en la comunidad humana hubiesen disminuido la correspondencia entre la organización política mundial y las exigencias objetivas del bien común universal ${ }^{13}$, por lo que deseaba que algún día se crease una "autoridad pública mundial|»14.

Ante la unificación del mundo, propiciada por el complejo fenómeno de la globalización, y ante la importancia de garantizar, además de otros bienes colectivos, el bien representado por un sistema económicofinanciero mundial libre, estable y al servicio de la economía real, la enseñanza de la Pacem in Terris se presenta, hoy en día, aún más viva y necesitada urgentemente de concreciones.

[14] El mismo Benedicto XVI, siguiendo las trazas de la Pacem in Terris, ha expresado la necesidad de constituir una autoridad política mundial 15 , que abarca una agenda global de cuestiones a tratar cada vez más amplia. Podemos pensar, por ejemplo, en la paz y la seguridad, en el desarme y el control de armamentos, en la promoción y la tutela de los derechos humanos fundamentales, en el "gobierno" de la economía y en las políticas de desarrollo, en la gestión de los flujos migratorios y en la seguridad alimentaria o en la tutela del medio ambiente. Resulta cada vez más evidente en todos estos ámbitos la creciente interdependencia entre los Estados y las regiones del mundo y la necesidad de respuestas no sólo sectoriales y aisladas, sino sistemáticas e integradas, inspiradas por la solidaridad y por la subsidiaridad y orientadas hacia el bien común universal.

Como recuerda Benedicto XVI, si no se sigue ese camino, incluso

el derecho internacional, no obstante los grandes progresos alcanzados en los diversos campos, correría el riesgo de estar condicionado por los equilibrios de poder entre los más fuertes ${ }^{16}$.

\footnotetext{
${ }^{13}$ Juan XXIII (1963) Pacem in terris, n. 70.

14 JuAN XXIII (1963) Pacem in terris, nn. 71-74.

${ }^{15}$ BeNedICTO XVI (2009) Caritas sin veritate, n. 67.

$16 \mathrm{lbid}$.
} 
La finalidad de una autoridad pública, recordaba Juan XXIII en Pacem in Terris, es ante todo el servicio del bien común, por lo que aquélla debe dotarse de estructuras y mecanismos adecuados y eficaces, a la altura de la propia misión y de las expectativas puestas en ella. Esto es especialmente cierto en un mundo globalizado que hace que las personas y los pueblos cada vez estén más interconectados y sean más interdependientes, pero que muestra también el egoísmo y el peso de los intereses sectoriales, entre los cuales se cuentan los mercados monetarios y financieros, de carácter sobre todo especulativo, que son perjudiciales para la «economía real», en especial la de los países más débiles.

[15] Es este un proceso complejo y delicado. Una autoridad supranacional de este tipo debe, por supuesto, ser introducida realista y gradualmente y favorecer sistemas monetarios y financieros eficientes y eficaces, es decir, mercados libres y estables, encuadrados por un marco jurídico adecuado, funcionales a un desarrollo sostenible y al progreso social de todos e inspirados por los valores de la caridad en la verdad ${ }^{17}$. Una autoridad de horizonte planetario no puede ser impuesta por la fuerza, sino que debe ser expresión de un acuerdo libre y compartido que vaya más allá de las exigencias permanentes e históricas del bien común mundial y no sea fruto de presiones o violencia. Una autoridad de este tipo debe surgir del proceso de progresiva maduración de las conciencias y de las libertades, así como de la conciencia de las crecientes responsabilidades existentes. La confianza mutua, la autonomía y la participación no pueden, consecuentemente, considerarse superfluas. El consenso debe ir involucrando a un número de países cada vez mayor, adheridos por convicción y por un sincero diálogo que no margine, sino que valore las opiniones minoritarias. La autoridad mundial debe, pues, lógicamente implicar a todos los pueblos en una colaboración a la que éstos han de contribuir con el patrimonio de su propia civilización y sus valores.

[16] La constitución de una autoridad política mundial debe ser precedida por una fase preliminar de acuerdo, de la que emerja una institución "legitimada", capaz de proporcionar ser guía eficaz y, al mismo tiempo, de permitir a cada país que exprese y procure su propio bien particular. El ejercicio de una autoridad semejante, puesta al servicio del bien de todos y de cada uno, estará necesariamente super partes, es decir, por encima de toda visión parcial y de todo bien particular, y será ordenada a la realización del bien común. Sus decisiones no deberán ser el resultado del poder previo de los países más desarrollados sobre los países más débiles, sino que deben ser asumidas para el interés de todos y no sólo para

17 Ibid. 
ventaja de algunos grupos, formados sea por "lobbies" privados o por gobiernos nacionales.

Una institución supranacional, expresión de una "comunidad de naciones», por otra parte, no duraría mucho tiempo, si no son reconocidos y plenamente respetados la diversidad de los países, en el plano cultural, de recursos materiales e inmateriales y de los aspectos históricos y geográficos. Si no existiese un consenso compartido y alimentado por una ininterrumpida comunión moral de la comunidad mundial, la eficacia de esta autoridad quedaría debilitada.

Lo que vale para las naciones sirve también en el orden mundial. La persona no está hecha para un servicio incondicional a la autoridad, cuya tarea es ponerse al servicio de la propia persona, en coherencia con la preeminencia de la dignidad del ser humano. Del mismo modo, los gobiernos no han de servir incondicionalmente a la autoridad mundial, pues ante todo es ésta la que debe ponerse al servicio de los diversos países miembros, de acuerdo con el principio de subsidiaridad, creando, entre otras, las condiciones socioeconómicas, políticas y jurídicas indispensables para la existencia de mercados eficientes y eficaces, que no estén excesivamente protegidos por políticas nacionales paternalistas, ni debilitados por "déficit" sistemáticos en las finanzas públicas y en los productos nacionales que, de hecho, impiden que los mercados actúen como instituciones abiertas y competitivas en un contexto mundial.

[17] En la tradición del magisterio de la Iglesia, retomada con vigor por Benedicto $\mathrm{XV} \mathrm{I}^{18}$, el principio de subsidiaridad debe regular las relaciones entre el Estado y las comunidades locales, entre las instituciones públicas y las instituciones privadas, sin excluir a las monetarias y financieras. Asimismo, en un momento posterior, debe regular las relaciones entre una eventual y futura autoridad pública mundial y las instituciones regionales y nacionales. Tal principio garantiza tanto la legitimidad democrática, como la eficacia de las decisiones de quienes han de tomarlas y permite respetar la libertad de las personas $y$ de las comunidades humanas $y$, al mismo tiempo, responsabilizarlas en relación a los objetivos y deberes que les afectan.

[18] Según la lógica de la subsidiaridad, la autoridad superior ofrece su ayuda (subsidium), "cuando" la persona y los actores sociales y financieros son intrínseca-

${ }^{18}$ Benedicto XVI (2009) Caritas sin veritate, nn. 56 y 67. 
mente incapaces para hacer por sí mismos lo que les corresponde ${ }^{19}$. Por el principio de solidaridad se construye una relación duradera y fecunda entre la sociedad civil planetaria y una autoridad pública mundial, cuando los Estados, los cuerpos intermedios, las diversas instituciones -incluso las económicas y financieras- y los ciudadanos toman sus decisiones en la perspectiva del bien común mundial, que trasciende el nacional.

El gobierno de la globalización»-se lee en Caritas in Veritate- debe ser de tipo subsidiario, articulado en múltiples niveles y diversos planos, que colaboren recíprocamente ${ }^{20}$. Sólo así se puede evitar el aislamiento de una autoridad central burocratizada, que sufriese el riesgo de deslegitimación por estar demasiado separada de las realidades en que se funda y pudiese caer fácilmente en tentaciones paternalistas, tecnocráticas o autoritarias.

[19] Sin embargo, antes de llegar a la constitución de una autoridad pública con competencia universal de este tipo queda aún un largo camino. Lógicamente el proceso de reforma habría de desarrollarse teniendo como punto de partida la Organización de Naciones Unidas, a causa de la amplitud mundial de sus responsabilidades, de su capacidad de reunir a las naciones de la tierra y de la diversidad de sus propias tareas y de las de sus agencias especializadas. El fruto de estas reformas debería ser una mayor capacidad para adoptar políticas y opciones vinculantes orientadas a la realización del bien común local, regional y mundial. Entre las políticas urgentes aquellas figuran las relativas a la justicia social global: políticas financieras y monetarias que no dañen los países más débiles ${ }^{21}$ y políticas dirigidas a la existencia real de mercados libres y estables con una distribución equitativa de la riqueza mundial, incluso mediante formas inéditas de solidaridad fiscal global, a la que se aludirá más adelante.

[20] En el proceso de la constitución de una autoridad política mundial hemos de vincular las cuestiones de governance (el sistema de simple coordinación horizontal sin una autoridad "super partes") con aquellas de unshared government (el sistema que, además de la coordinación horizontal, establece una autoridad "super partes") funcional y gradualmente proporcionada al desarrollo de una sociedad política mundial. La constitución de una autoridad política mundial no

\footnotetext{
${ }^{19}$ BeNEDICTO XVI (2009) Caritas sin veritate, n. 57.

$20 \mathrm{lbid}$.

${ }^{21}$ Concilio Vaticano II (1965) Constitución pastoral Gaudium et Spes, n. 70.
} 
podrá ser lograda sin la práctica previa del multilateralismo, no sólo diplomático, sino principalmente en el ámbito de los programas de desarrollo sostenible y de paz. No podremos alcanzar un gobierno mundial si no se da forma de expresión política a las interdependencias y cooperaciones preexistentes.

\section{Hacia una reforma del sistema financiero y monetario inter- nacional que responda a las exigencias de todos los pueblos}

[21] Las dificultades más relevantes en materia económica y financiera derivan de la ausencia de un conjunto eficaz de estructuras capaces de garantizar, además de un sistema de "governance", un sistema de "government" de la economía y de las finanzas internacionales.

¿Qué se puede decir de esta perspectiva? ¿Qué pasos concretos deben darse?

[22] En el actual sistema económico y financiero mundial hay dos elementos determinantes a ser señalados: el primero es la disminución progresiva de la eficiencia de las instituciones de Bretton Woods, desde los inicios de los años setenta. El Fondo Monetario Internacional en particular ha perdido una característica esencial para garantizar la estabilidad de las finanzas mundiales: la reglamentación de la creación general de moneda y la supervisión del monto de riesgo del crédito asumido por el sistema. En definitiva, ya no contamos con aquel «bien público universal» que era la estabilidad del sistema monetario mundial.

[23] El segundo factor es la necesidad de un "corpus" mínimo compartido de reglas necesarias para la gestión del mercado financiero global, que ha crecido mucho más rápidamente que la "economía real», habiéndose desarrollado velozmente, efecto por un lado de la supresión generalizada de los controles sobre los movimientos de capitales y de la tendencia a desregular las actividades bancarias y financieras $y$, por el otro, con los progresos de la técnica financiera favorecidos por los instrumentos informáticos.

[24] En el plano estructural, en la última parte del siglo XX la moneda y las actividades financieras globales crecieron mucho más rápidamente que la producción de bienes y servicios. Ese contexto ha llevado a una disminución de la calidad del crédito hasta exponer a los institutos de crédito a un riesgo mayor del que es razonablemente sostenible. Basta observar lo acaecido a grandes y pequeños institutos de crédito en el contexto de las crisis sucedidas en los años ochenta y noventa del siglo anterior, y finalmente en la de 2008. 
En la última parte del siglo XX se desarrolló la tendencia a definir las orientaciones estratégicas de política económica y financiera al interior de clubes y de grupos, más o menos amplios, de los países más desarrollados. Sin negar los aspectos positivos de este enfoque, no se puede ignorar que de esa forma no parece respetarse plenamente el principio de representación, en concreto la de los países menos desarrollados o emergentes.

[25] La necesidad de tener en cuenta la voz de un número mayor de países ha llevado a la ampliación de dichos grupos, pasando así del G7 al G20. Ésta ha sido una evolución positiva, en cuanto ha corresponsabilizado de las orientaciones económicas y financieras globales a aquellos países con una población más elevada, en vías de desarrollo y emergentes.

En el ámbito del G20 pueden, por lo tanto, madurar directrices concretas que, elaboradas en los ámbitos técnicos adecuados, puedan orientar a los órganos competentes nacionales y regionales para la consolidación de las instituciones existentes y la creación de nuevas instituciones con instrumentos internacionales apropiados y eficaces.

Los propios líderes del G20 afirman en la Declaración final de Pittsburgh de 2009 que la crisis económica demuestra la importancia de comenzar una nueva era de la economía global basada en la responsabilidad. Para afrontar la crisis y abrir una nueva era de la responsabilidad, además de medidas de tipo técnico y de corto plazo, los líderes proponen una

reforma de la arquitectura global para afrontar las exigencias del siglo XXI [y, por tanto] un marco que permita definir las políticas y las medidas comunes con el objeto de producir un desarrollo global sólido, sostenible y equilibrado22.

[26] Es preciso por tanto, dar inicio a un proceso de reflexión profunda y de reformas que abran vías creativas y realistas que tiendan a valorar los aspectos positivos de las instituciones y de los foros ya existentes.

La reforma del sistema monetario internacional $y$, en particular, el empeño para dar vida a una cierta forma de control monetario global, desde luego ya implícita en los estudios del Fondo Monetario Internacional merece una atención específica. En cierta medida, esto equivale a poner en discusión los sistemas de cambio existentes para encontrar modos eficaces de coordinación y supervisión. Este proceso ha de

${ }^{22}$ Leader's Statement, Cumbre de Pittsburgh, 24/25-IX-2009. Cfr. anexo 1, párrafo 1; G20 Framework for Strong, Sustainable, and Balanced Growth, \& 1; Leader's Statement, nn 18, 13. 
involucrar también los países emergentes y en vías de desarrollo para definir las etapas de adaptación gradual de los instrumentos existentes.

En esta perspectiva se diseña la exigencia de un organismo que ejerza las funciones de una especie de «Banco central mundial» regulador del flujo y del sistema de intercambios monetarios, con el mismo criterio que los bancos centrales nacionales. Para ofrecer respuestas adecuadas a las cuestiones actuales hay que redescubrir la lógica de fondo (paz, coordinación y prosperidad común) que condujo a los acuerdos de Bretton Woods. Este proceso podría realizarse en ámbitos regionales fortaleciendo instituciones existentes como, por ejemplo, el Banco Central Europeo, lo que sin embargo requeriría no sólo una reflexión económica y financiera, sino ante todo, una reflexión política para constituir instituciones públicas apropiadas para garantizar la unidad y la coherencia de las decisiones comunes.

[27] Estas medidas deberían ser concebidas como primeros pasos en la perspectiva de una autoridad pública con competencia universal y como una primera etapa de un más amplio esfuerzo de la comunidad mundial por orientar sus instituciones hacia la realización del bien común. Teniendo en cuenta que las dinámicas presentes pueden acentuarse, pero también acompañarse de cambios que hoy sería en vano tratar de prever, en este proceso deberán seguir otras etapas.

[28] En dicho proceso, hay que recuperar la primacía de lo espiritual y de la ética y, unido a esto, la primacía de la política -responsable del bien común- sobre la economía y las finanzas, que deben regresar al interior de su real vocación y de su función, incluida la social que tiene relación con sus evidentes responsabilidades para con la sociedad, de manera que den vida a mercados e instituciones financieras efectivamente al servicio de la persona, es decir capaces de responder a las exigencias del bien común y de la fraternidad universal, trascendiendo toda forma de economicismo grosero y de mercantilismo performativo.

A partir de dicho enfoque de tipo ético, es conveniente reflexionar, por ejemplo, sobre:

a) las medidas de tasación fiscal de las transacciones financieras, mediante cuotas equitativas, moduladas con gastos proporcionados a la complejidad de las operaciones, sobre todo las que se realizan en el mercado "secundario». Dicha tasa sería muy útil para promover el desarrollo global y sostenible según principios de justicia social y de solidaridad y podría contribuir a formar una reserva mundial de apoyo a los países afectados por la crisis, así como al saneamiento de su sistema monetario y financiero; 
b) las formas de recapitalización de los bancos, incluso con fondos públicos condicionados a comportamientos «virtuosos» y orientados al desarrollo de la «economía real»;

c) sobre la definición de ámbito de actividad del crédito ordinario y del Investment Banking, que permitiría una disciplina más eficaz de los «mercados paralelos» que actúan sin controles ni límites.

[30] Se requiere tiempo para construir amplios consensos con realismo, pero el horizonte del bien común universal con sus exigencias ineludibles debe tenerse siempre presente. Por ello todos los que, en las universidades y en las diferentes instituciones llamadas a formar las clases dirigentes del mañana, se dediquen a prepararlas, lo hagan de manera que éstas puedan asumir sus propias responsabilidades de discernimiento y de servicio del bien público global, en un mundo que cambia constantemente. Hay que llenar el vacío existente entre la formación ética y la preparación técnica, poniendo en evidencia especialmente la ineludible sinergia entre los dos planos de la praxis y de la poiésis.

Este esfuerzo se requiere a todos aquellos que influyen y orientan la opinión pública mundial, para que pueda afrontar este mundo nuevo sin angustia y con esperanza y solidaridad.

\section{Conclusiones}

[31] En la actual incertidumbre de una sociedad capaz de movilizar medios ingentes, cuya reflexión en el campo cultural y moral resulta sin embargo incapaz de orientar la consecución de los propios fines, no debemos rendirnos sino que ante todo hemos de construir un futuro con sentido para las generaciones venideras. No hemos de temer la propuesta de innovaciones, aunque puedan desestabilizar preexistentes equilibrios de fuerza que dominan a los más débiles. Estas cosas nuevas son una semilla sembrada en tierra, que germinará y no tardará en dar frutos.

Como ha declarado Benedicto XVI, en todos los ámbitos -social, político, económico y profesional- son necesarias personas y actores motivados para servir y promover, mediante una vida buena, el bien común ${ }^{23}$. Sólo ellos lograrán vivir y

${ }^{23}$ Benedicto XVI (2009) Caritas in veritate, n. 71 y Juan Pablo II (1991) Centesimus annus, n. 52. 
ver más allá de la apariencia de las cosas, percibiendo la diferencia entre lo real existente y lo posible nunca antes experimentado.

[32] Pablo VI subrayó la fuerza revolucionaria de la «imaginación prospectiva», capaz de percibir en el presente las posibilidades que en él están inscritas y de orientar a las personas hacia un futuro nuevo ${ }^{24}$ : con la liberación de la imaginación, la persona libera su propia existencia y mediante el compromiso de imaginación comunitaria es posible transformar no sólo las instituciones, sino también los estilos de vida y suscitar un futuro mejor para todos los pueblos.

Con el trascurso del tiempo los Estados modernos se han convertido en estructuras que concentran la soberanía en el interior del propio territorio, aunque progresivamente las condiciones sociales, culturales y políticas han cambiado con el aumento de su interdependencia -de manera que parece natural pensar en una comunidad internacional cada vez más integrada y regulada por un ordenamiento compartido- pero no ha vendió a menos cierta forma degradada de nacionalismo, según la que el Estado considera que puede alcanzar autárquicamente el bien de sus propios ciudadanos.

Esto nos parece hoy irreal y anacrónico, ya que todas las naciones, pequeñas - grandes, junto a sus gobiernos, están llamadas a superar dicho "estado de naturaleza» que considera a los Estados en perenne lucha entre sí. A pesar de algunos aspectos negativos, la mundialización está unificando más a los pueblos y los impulsa hacia un nuevo "estado de derecho» supranacional, fundado en una más intensa y fecunda colaboración. Con una dinámica análoga a la que en el pasado puso fin a la lucha "primitiva» entre clanes y reinos rivales para poder constituir los Estados nacionales, la humanidad hoy tiene que comprometerse en la transición de una situación de luchas arcaicas entre entidades nacionales hacia un nuevo modelo de sociedad internacional con mayor cohesión, poliárquica, respetuosa de la identidad de cada pueblo, integrando las múltiples riquezas de una única humanidad. Esta transición, por lo demás tímidamente iniciada, asegurará a los ciudadanos de todos los países -cualquiera que sea la dimensión o fuerza que posea- paz y seguridad, desarrollo, mercados libres, estables y transparentes.

\footnotetext{
${ }^{24}$ Pablo VI (1971) Octogesima adveniens, n. 37 [En el mismo documento habla de "imaginación social", cfr. n. 19, ndt].
} 
Así como dentro de cada Estado [...] el sistema de la venganza privada y de la represalia ha sido sustituido por el imperio de la ley-advierte Juan Pablo II-, así también ahora es urgente que semejante progreso tenga lugar en la Comunidad internacional ${ }^{25}$.

[33] Cuando están en juego bienes vitales pertenecientes a toda la familia humana que los Estados, aisladamente no son capaces de promover ni de proteger, llega el tiempo para pensar en instituciones con competencia universal.

Existen, pues, las condiciones para la superación definitiva de un orden internacional «westfaliano», en el que los Estados perciben la exigencia de la cooperación, pero no captan la oportunidad de una integración de las propias soberanías para el bien común de los pueblos.

[34] Reconocer y aceptar conscientemente esta nueva dinámica mundial para realizar el bien común universal es tarea de las generaciones presentes. Ciertamente, esta transformación se hará con la transferencia gradual y equilibrada de una parte de las competencias nacionales a una autoridad mundial y a las autoridades regionales, lo que es necesario en un momento en el que el dinamismo de la sociedad humana y de la economía y el progreso de la tecnología trascienden las fronteras, que de hecho están difuminadas en un mundo globalizado.

La concepción de una nueva sociedad, la construcción de nuevas instituciones con vocación y competencia universales, son un derecho y un deber de todos, sin distinción alguna. Está en juego el bien común de la humanidad y su mismo futuro.

[35] Cada cristiano recibe, en este contexto, una especial llamada del Espíritu a comprometerse con decisión y generosidad, para que las múltiples dinámicas presentes se orienten en la perspectiva de la fraternidad y del bien común. Para el desarrollo integral de los pueblos y de cada persona se abren inmensas posibilidades. Como afirmaron los padres del Concilio Vaticano II, ésta es una misión al mismo tiempo social y espiritual que, en cuanto puede contribuir a ordenar mejor la sociedad humana, interesa en gran medida al reino de Dios ${ }^{26}$.

En un mundo en un rápido proceso de globalización, la referencia a una autoridad mundial es el único horizonte coherente con las nuevas realidades de nuestro tiempo y con las necesidades de la especie humana. Esta transición, sin embargo,

\footnotetext{
25 JuAn Pablo II (1991) Centesimus annus, n. 52.

${ }^{26}$ Concilio Vaticano II (1965) Constitución pastoral Gaudium et Spes, n. 39.
} 
dada la naturaleza herida de los seres humanos, no se realizará sin angustias y sufrimientos.

[36] La Biblia, con el relato de la torre de Babel (Génesis 11,19), advierte cómo la «diversidad» de los pueblos puede transformarse en instrumento de egoísmo y de división. En la humanidad es muy fuerte el riesgo de que los pueblos terminen por no comprenderse y que la diversidad cultural sea motivo de contraposiciones enfermizas. La imagen de la torre de Babel nos señala también que hay que liberarse de una «unidad» sólo aparente, en la que siguen presentes los egoísmos y las divisiones, puesto que los fundamentos de la sociedad no son estables. En ambos casos, Babel es la imagen de lo que pueblos e individuos pueden llegar a ser cuando no reconocen su intrínseca dignidad trascendente y su fraternidad.

El espíritu de Babel es la antítesis del Espíritu de Pentecostés (Hechos 2, 112), del designio de Dios para toda la humanidad, es decir, la unidad en la diversidad. Sólo un espíritu de concordia, superador de divisiones y conflictos, permitirá a la humanidad ser auténticamente una única familia, hasta llegar a concebir un mundo nuevo con la constitución de una autoridad pública mundial, al servicio del bien común. 